\title{
Phosphorus Nutrition and Selection against Leaf Chlorosis Related to Powdery Mildew Resistance in Cucumber
}

\author{
Steven P.C. Groot, Sierd Zijlstra, and Johannes Jansen \\ Centre for Plant Breeding and Reproduction Research, P. O. Box 16, NL-6700 AA Wageningen, \\ The Netherlands \\ Additional index words. Cucumis sativus, leaf necrosis, Sphaeroceca fuliginea, Ersyphe cichoracearum
}

\begin{abstract}
Powdery mildew-resistant (PMR) cultivars of cucumber (Cucumis sativus L.) grown in greenhouses in the Netherlands during winter show chlorosis on the full-grown leaves of the main stem. The symptoms are yellowing and occasional necrosis between the main veins of the leaves, resembling symptoms of $P$ toxicity. Severity of the chlorosis may vary from one winter to another. Variation is also observed in the severity of the symptoms between cultivars and individual plants of a cultivar. High $P$ nutrition results in an increase of the severity of chlorosis and provides a better discriminating environment for the selection of PMR genotypes that are less susceptible for leaf chlorosis.
\end{abstract}

Cucumber originates from the region of India and Nepal. When primitive germplasm is grown in greenhouses in the Netherlands, chlorosis or necrosis often develops on the leaves. This occurs especially under conditions of low light intensity and short days during autumn and winter. Modern cultivars bred for production in greenhouses in the Netherlands are adapted to growing under low light intensities and do. not show necrosis during winter.

The breeding line 'NPI' was introduced in 1967 (Kooistra, 1968) as a source of resistance toward powdery mildew [both Sphaerotheca fuliginea (Schlecht.) Pollaccii and Erysiphe cichoraceamm DC. ex Mérat]. During winter, plants of 'NPI' suffer from leaf chlorosis that gradually turns into necrotic spots and eventually leads to the death of larger parts of the leaf. Notwithstanding extensive breeding efforts, PMR cultivars free of leaf chlorosis during winter cultivation were not developed. This failure to observe segregation of leaf chlorosis susceptibility and powdery mildew resistance indicates that both traits are very tightly linked or that leaf chlorosis is a pleiotropic effect of the loci conditioning powdery mildew resistance. Pleiotropy has been described in barley (Hordeum vulgare L.) for a powdery mildew resistance gene that also causes leaf necrosis and yield decreases (Schwarzbach, 1976). In barley, the pleioptropic effects of this gene depend on the genetic background (Bjørnstad and Aastveit, 1990; Kjær et al., 1990).

Current PMR cultivars of cucumber show at least two types of chlorosis. A type called shoot chlorosis occurs on new leaves of the side shoots that develop after removal of the main stem top. This chlorosis is visible as small, light-green fields between the small veins and disappears when the leaf matures. Susceptibility for this type of shoot chlorosis is not related to powdery mildew resistance (Groot et al., 1989). A second type of chlorosis may develop on the leaves along the main stem, visible as yellowing and sometimes death of the area between the main veins. This type of leaf chlorosis susceptibility is related to powdery mildew resistance (den Nijs, 1984).

Received for publication 31 Dec. 1990. Accepted for publication 27 Sept. 1991 We thank the breeding companies De Ruiter Zonen B. V., Nunhems Zaden B. V., and Rijk Zwaan B.V. for the gift of seeds from the cultivars used in the experiments and T. Kramer for his suppport and critical comments on the manuscript. The cost of publishing this paper was defrayed in part by the payment of page charges. Under postal regulations, this paper therefore must be hereby marked advertisement solely to indicate this fact.
The leaf chlorosis susceptibility character reduces fruit yield of PMR cultivars in the winter. Therefore, growers use PMS cultivars requiring frequent use of fungicides. The need to decrease the use of fungicides in horticultural practice has created a high demand for PMR cultivars that are LCR.

In previous experiments, it was shown that the chlorosis symptoms are less severe when the PMR/LCS cultivars are grown in soil instead of rockwool, or when the plants are grafted on rootstock of Sicyos angulatus (L.) (den Nijs, 1984). These observations indicated a possible involvement of the root system, or nutrition in the occurrence of chlorosis. Previous studies with cucumber showed a positive correlation between susceptibility for chlorosis and P content of the leaves and of xylem exudate (Zijlstra et al., 1987). Selection for leaf chlorosis susceptibility and powdery mildew resistance is hampered by the variable expression of leaf chlorosis susceptibility. Selection efficiency could be improved by finding cultivation conditions that are more discriminating between LCS and LCR genotypes.

In the present study, the influences of extra $\mathrm{P}$ nutrition on the severity of chlorosis of both LCS and LCR cultivars was investigated by cultivating PMS and PMR cultivars on rockwool in a greenhouse. In addition, the effect of $\mathrm{P}$ nutrition on single plant selection of PMR/LCR genotypes was investigated.

\section{Material and Methods}

Plant material. Three PMR/LCS hybrid cultivars and three PMS/LCR hybrid cultivars of parthenocarpic slicing cucumbers from the same sources were used (Table 1). The powdery mil-

Table 1. Cucumber cultivars used and their traits and seed sources.

\begin{tabular}{lccl}
\hline \hline & \multicolumn{2}{c}{ Resistance } & \\
\cline { 2 - 3 } Cultivar & $\begin{array}{c}\text { Powdery } \\
\text { mildew }\end{array}$ & $\begin{array}{c}\text { Leaf } \\
\text { chlorosis }\end{array}$ & \multicolumn{1}{c}{ Seed source } \\
\hline Corona & No & Yes & De Ruiter Zonen B.V. \\
Sandra & No & Yes & Nunhems Zaden B.V. \\
Lucinde & No & Yes & Rijk Zwaan \\
Profito & Yes & No & De Ruiter Zonen B.V. \\
Bells & Yes & No & Nunhems Zaden B.V. \\
Cordoba & Yes & No & Rijk Zwaan \\
\hline
\end{tabular}

Abbreviations: LCR, leaf chlorosis resistant; LCS, leaf chlorosis susceptible; PMR, powdery mildew resistant; PMS, powdery mildew susceptible. 
dew resistance of the PMR hybrids was obtained from the line 'NPI' (Kooistra, 1968).

Cultural practices. Seeds were sown in vermiculite (day O) and seedlings were transplanted into small rockwool blocks 5 days later. In the nursery, the plants received continuous illumination (24 W.m ${ }^{-2}$ SONT-lamps, Philips) and extra $\mathrm{CO}_{2}$ (total $500 \mathrm{ppm}$ ) after day 14 . The side shoots were removed until the plants were $\approx 2 \mathrm{~m}$ long, the top of the main shoot was cut at that height, and two side shoots were allowed to grow further.

Experiment design. Since it was not possible to apply two levels of $\mathrm{P}$ nutrition to plants within the same greenhouse compartment, two compartments were used. Except for P nutrition, conditions in both compartments were almost identical. However, compartment 1 was surrounded by other compartments, while one side of compartment 2 faced the northern outside of the greenhouse complex. For the latter, this resulted in a faster shift in temperature from day (23C) to night (19 C). To test whether the results obtained were an effect of $\mathrm{P}$ nutrition and not due to compartment effects, the experiment was repeated in two succesive winters, switching the P nutrition levels. During the first winter, $1.5 \mathrm{mmP}$ (standard) was used in compartment 1 and $3.0 \mathrm{~mm} \mathrm{P}$ in compartment 2; during the second winter $3.0 \mathrm{~mm} P$ was applied to plants in compartment 1 and $1.25 \mathrm{~mm}$ $\mathrm{P}$ (standard) in compartment 2. The standard P level was lowered according to changes in recommendation of the Greenhouse Crop Experimental Station (Naaldwijk, The Netherlands) for cucumber cultivation on rockwool. The other nutrients were given as recommended by the Greenhouse Crop Experimental Station (18 mu N, $8 \mathrm{~mm} \mathrm{~K}, 4.15 \mathrm{~mm} \mathrm{Ca}, 1.38 \mathrm{~mm} \mathrm{Mg}, 1.15$ $\mathrm{mm} \mathrm{S}, 25 \mu \mathrm{M} \mathrm{B}, 15 \mu \mathrm{M} \mathrm{Fe}, 10 \mu \mathrm{M} \mathrm{Mn}, 5.3 \mu \mathrm{M} \mathrm{Zn}, 0.8 \mu \mathrm{M}$ $\mathrm{Cu}$, and $0.5 \mu \mathrm{M} \mathrm{Me}$ ). For $\mathrm{P}$ at $3.0 \mathrm{~mm}, 10 \%$ of the $\mathrm{KNO}_{3}$ was replaced with $\mathrm{KH}_{2} \mathrm{PO}_{4}$. The nutrient solution was applied by means of drip irrigation.

For the experiment in the first winter (1988-89), seeds were sown on 25 Nov. 1988 and the plants were transferred from the nursery to the greenhouse compartments at day 32 of the experiment. For the experiment in the second winter (1989-90), seeds were sown on 10 Nov. 1989 and the plants were transferred to the greenhouse at day 26 .

To reduce the expected effect of environmental variability (especially variations in level of irradiation), the experiments were laid out in incomplete blocks of four plants of different cultivars by means of a computer program described in Jansen et al. (1992). The experiments were bordered by a single guard row. There were 18 and 21 replications of the cultivars in compartment: 1 and 2, respectively.

Statistical analysis. Statistical analyses were carried out on the proportion of chlorotic leaves, by means of a generalized linear model (McCullagh and Nelder, 1989) for binary data involving the probit link function. Calculations were done using the statistical package Genstat (Payne et al., 1987). Within the separate experiments, the effect of $\mathrm{P}$ is confounded with the effect of greenhouse compartments.

Chlorosis classification. The severity of chlorosis and necrosis of the individual leaves was classified according to a scale where; $\mathrm{O}=$ green leaf without symptoms; 1 = leaf with one or a few yellowing spots; 2 = leaf yellowing between the veins; $3=$ most of leaf yellowing, sometimes with pale spots; $4=$ leaf yellowing with necrotic (dead) spots.

\section{Results}

Chlorosis in Winter 1988-89. Chlorosis of the older leaves was recorded on day 61 for leaves 3 to 9 , numbered from the cotyledons upward. At that time, leaves of the LCR plants showed no symptoms, but most of the LCS plants exhibited chlorosis on leaves 3, 4, and 5 (Fig. 1; 'Cordoba', PMR/LCS). For 'Cordoba' there was variation between the individual plants with respect to the severity of the symptoms, and chlorosis was most prominent on the oldest leaves. With $3.0 \mathrm{~mm}$ P, chlorosis symptoms were more severe than with $1.5 \mathrm{mmP}$ (Fig. 1). Although variation among individual plants regarding the severity of chlorosis was also observed for 'Profito' and 'Bells' (both PMR/ LCS), there were considerable differences between the three LCS cultivars. Leaf 4 of the three PMS/LCR cultivars Corona, Sandra, and Lucinde were all green (Fig. 2). At both P nutrition levels, leaves of 'Cordoba' were more chlorotic than leaves of 'Bells', while leaves of 'Profito' showed an intermediate level of chlorosis. With $3.0 \mathrm{~mm}$ P, the severity of the symptoms increased considerably for leaf 4 of 'Cordoba' and 'Profito' but not for 'Bells' (Fig. 2). In the course of" the experiment the severity of the chlorosis gradually increased for leaves of the LCS plants (data not shown).

Leaves 3, 4, and 5 from 'Bells' were less affected than those of 'Profito' or 'Cordoba' (Table 2). There were significant effects on chlorosis by cultivars $(\mathrm{P}<0.001)$, leaf number $(\mathrm{P}<$ $0.001)$, and $\mathrm{P}$ nutrition $(\mathrm{P}<0.01)$.

Chlorosis in Winter 1989-90. Although the second experiment was started relatively 2 weeks earlier than the first one, the leaves from the LCS plants did not develop chlorosis before

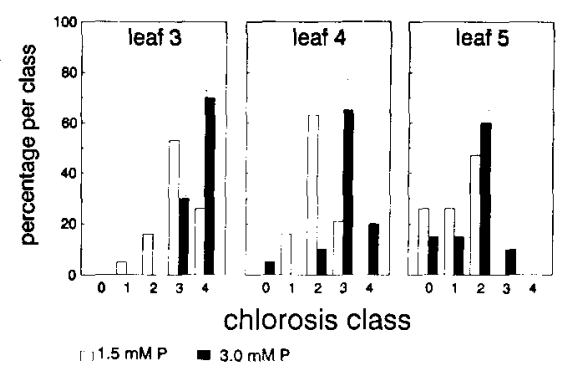

Fig. 1. Chlorosis of leaves 3, 4, and 5 of 'Cordoba' cucumber plants at day 61 of the 1988-89 experiment. Data are presented as the percentage of plants from which the specified leaf is classified in chlorosis classes $0-4$.
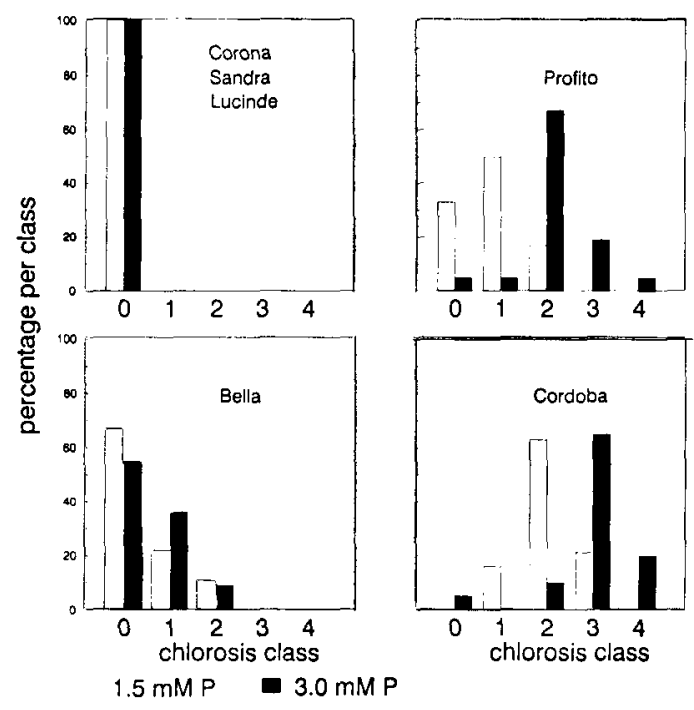

Fig. 2. Chlorosis of leaf 4, as observed on day 61 of the 1988-89 experiment. Data are the percentage of cucumber plants with leaf 4 classified for chlorosis as indicated. 
Table 2. Percentage of PMR/LCS 'Cucumber' plants on day 61 of the 1988-89 experiment on which leaf 3, 4, or 5 was chlorotic (chlorosis score at least 2).

\begin{tabular}{lcrcr}
\hline \hline \multirow{2}{*}{ Cultivar } & \multirow{2}{*}{$\begin{array}{c}\text { P level } \\
(\mathrm{mM})\end{array}$} & 3 & \multicolumn{3}{c}{ Leaf no. } \\
\cline { 3 - 5 } & & & Percent & 5 \\
\hline \multirow{3}{*}{ Profito } & 1.5 & 100 & 67 & 28 \\
& 3.0 & 100 & 95 & 62 \\
Bella & 1.5 & 44 & 37 & 26 \\
& 3.0 & 82 & 45 & 14 \\
Cordoba & 1.5 & 100 & 100 & 74 \\
& 3.0 & 100 & 95 & 85 \\
\hline
\end{tabular}

Table 3. Average percentages of leaves 3-15 of the main stem that showed chlorotic symptoms (chlorosis score at least 1) on days 91 and 103 of the 1989-90 experiment.

\begin{tabular}{|c|c|c|c|c|}
\hline \multirow[b]{4}{*}{ Cultivar } & \multicolumn{4}{|c|}{ Days after sowing } \\
\hline & \multicolumn{2}{|c|}{91} & \multicolumn{2}{|c|}{103} \\
\hline & \multicolumn{4}{|c|}{ Phosphorous concn (mM) } \\
\hline & 1.25 & 3.0 & 1.25 & 3.0 \\
\hline LCR & \multicolumn{4}{|c|}{ Percent } \\
\hline Corona & 10.9 & 14.7 & 9.2 & 25.2 \\
\hline Sandra & 13.5 & 19.2 & 25.1 & 40.2 \\
\hline Lucinde & 23.6 & 22.5 & 18.3 & 32.0 \\
\hline \multicolumn{5}{|l|}{ LCS } \\
\hline Profito & 25.1 & 86.7 & 72.1 & 82.4 \\
\hline Bells & 12.9 & 68.0 & 72.7 & 87.3 \\
\hline Cordoba & 44.5 & 87.2 & 56.5 & 88.9 \\
\hline
\end{tabular}

the end of January, around day 80 , strikingly the same period of the year as the 1988-1989 experiment. At that time, most of the plants had already produced their first fruits and passed a height of $2 \mathrm{~m}$. In Winter 1989-90, chlorosis of the LCS plants was not limited to the oldest leaves but also affected the other leaves on the main stem of most of the LCS plants that exhibited chlorosis.

On day 82, chlorosis on leaves 3,4 , and 5 was recorded. At that time, almost all plants of LCR cultivars were without symptoms in both compartments. Chlorosis symptoms on leaves 3 , 4 , and 5 affected $13 \%$ of LCS cultivars with $1.25 \mathrm{mmP}$ (compartment 2) and 54\% with $3.0 \mathrm{~mm} \mathrm{P}$ (compartment 1). As in the 1988-89 experiment, at both P nutrition levels, leaves of 'Bells' were relatively less affected than those of 'Profito' or 'Cordoba'.

During the following weeks, the severity of the chlorosis symptoms increased gradually. More leaves were affected on the plants of LCS cultivars. At day 91, for leaves 3, 4, or 5 of the LCS cultivars, $51 \%$ of the leaves were chlorotic at $1.25 \mathrm{~mm}$ $\mathrm{P}$ and $79 \%$ at $3.0 \mathrm{~mm}$ P. For the LCR cultivars, the percentages were 26 and 20, respectively. When the severity of chlorosis for leaves 3 to 15 was expressed as the average percentage on day 91, a clear distinction between LCR and LCS cultivars existed only at $3.0 \mathrm{~mm} P$ (Table 3 ). At day 103 , at $1.25 \mathrm{~mm}$, most of the leaves from the LCR plants were still green, whereas more chlorosis was observed on their leaves at $3.0 \mathrm{~mm} \mathrm{P}$. At this time, leaves of the LCS plants at $1.25 \mathrm{~mm}$ P were only slightly less chlorotic than those at $3.0 \mathrm{~mm}$ P (Table 3 ). With $3.0 \mathrm{mMP}$, it was possible to distinguish statistically between LCR and LCS cultivars ( $\mathrm{P}<0.001$ ) on days 91 and 103 (Table $3)$. With $1.25 \mathrm{~mm} P$, it was impossible or very difficult to distinguish between LCR and LCS cultivars on day 91. On day
103, however, $1.25 \mathrm{mmP}$ provided a clear distinction between LCR and LCS cultivars $(\mathrm{P}<0.01)$. These results indicate that a higher P level may lead to earlier development of many chlorotic leaves in LCS cultivars compared with LCR cultivars, thus facilitating an earlier detection of chlorosis susceptibility of PMR cultivars.

\section{Discussion}

The symptoms of chlorosis related to powdery mildew resistance in cucumber are a yellowing between the main veins that eventually may result in necrosis of the leaves. In both winters, PMS plants barely showed this type of chlorosis, while it was present with most of the PMR plants (Fig. 2; Tables 2 and 3). Variation in expression of the susceptibility for chlorosis was also visible., In both experiments, chlorosis of the leaves on the main stem started at the same time of winter. While in Winter 1988-89, the symptoms were most severe on-the older leaves, in Winter 1989-90 most of the leaves of the main stem were affected. The experiments were performed in successive years and the second experiment was planted 2 weeks earlier than the first. Induction of this type of chlorosis may be affected by length of photoperiod or changes in photoperiod. Attempts to induce PMR-related leaf chlorosis in the greenhouse during other seasons, by severely restricting the amount of light under otherwise natural light conditions in the greenhouse, were not successful (S.P.C.G. and S.Z., unpublished).

Considerable variation in severity of chlorosis symptoms was observed among and within cultivars. Since hybrid cultivars were used, little genetic variation should be expected. Therefore, variation among plants of the same cultivar most likely resulted from differences in microenvironment within the greenhouse compartments. This underlines the need for finding a selection environment that is highly discriminating between PMR genotypes that are LCS or LCR. In both winters, chlorosis of the powdery mildew resistance was most evident if supplied with $3.0 \mathrm{~mm}$ P. Apparently, the differences in chlorosis were not due to a compartment effect. Therefore, identification of plants with an LCS genotype was improved with addition of extra $\mathrm{P}$ to the nutrient solution. However, it is also important that plants with an LCR genotype are not rejected when coincidentally showing chlorosis due to extra P nutrition. In the beginning, at day 91 in the second experiment, the frequency of wrongly rejected plants with LCR genotype is influenced only slightly by the level of P nutrition. But later, many of the LCR plants developed chlorosis on some of their leaves with $3.0 \mathrm{~mm}$ $\mathrm{P}$, and might wrongly be rejected; however, with $1.25 \mathrm{~mm} \mathrm{P}$, this was only a small portion. Apparently, $3.0 \mathrm{mmP}$ results in improved segregation during an earlier stage of plant development. At that stage, the advantages were a low likelihood of rejection of LCR genotypes and a high likelihood of the rejection of LCS genotypes.

Cucumber leaves are extremely susceptible to mechanical or chemical stress, which may also induce chlorotic or necrotic spots that are difficult to distinguish from a slight susceptibility to PMR-related leaf chlorosis. We suggest that a moderate selection pressure should be used on leaf chlorosis beyond the threshold zero. The threshold level of chlorosis should be chosen to minimize the frequency that plants of LCS genotypes are wrongly retained, whereas plants with LCR genotype should be retained at a high frequency.

$\mathrm{P}$ toxicity, visible as chlorosis and necrosis of the leaves, has been described for soybean (Glycine max L. Merr.) (Howell and Bernard, 1961; Shive, 1981), lupin (Lupinus luteus L.) (Warren 
and Benzian, 1959), clover (Trifolium subterraneum L.), and oats Avena sativa L.) (Rossiter, 1952). The mechanism of P toxicity is rather complex, but there are strong indications of interaction of P with the bio-availability of iron (Bienfait, 1989; Elliot and Läurchli, 1985), magnesium (Hipp and Gerard, 1969), or zinc (Marschner et al., 1990). Iron-deficiency chlorosis mostly occurs on young or terminal leaves, as can be observed with cucumber plants grown on Fe-deficient nutrient solutions (Groot et al., 1989). This observation makes it unlikely that powdery mildew resistance-related chlorosis is the result of a reduced uptake of Fe. However, an interaction of high levels of $\mathrm{P}$ in the older leaves with $\mathrm{Fe}$ or other metal ions, resulting in reduced bio-availability of Fe, cannot be excluded. Measurement of $\mathrm{Mg}$ and $\mathrm{Mn}$ levels in leaves of PMS and PMR cultivars in previous experiments did not reveal reduced levels of these elements in the leaves of the PMR cultivars (Zijlstra et al., 1987). Moreover, Mg deficiency results in chlorosis that resembles symptoms of shoot chlorosis and differs from the powdery mildew resistance-related chlorosis (Groot et al., 1989).

The symptoms as observed in the present experiment on the older leaves of the PMR plants were similar to those described by Marschner et al. (1990) for P toxicity induced in leaves of young cucumber plants grown on a nutrient solution with low Zn nutrition $(0.15 \mu \mathrm{M})$. However, Zn deficiency-induced P toxicity mainly occurs at high light intensity (Marschner and Cakmak, 1989), while the PMR-related chlorosis is typical for the winter season, with low light intensity. This relationship indicates the existence of several mechanisms causing $\mathrm{P}$ toxicity in cucumber.

\section{Literature Cited}

Bienfait, H.F. 1989. Prevention of stress in iron metabolism of plants. Acts Bet. Neerl. 38:105-129.

Bjørnstad, A. and K. Aastveit. 1990. Pleiotropic effects on the $m l-o$ mildew resistance gene in barley in different genetical backgrounds. Euphytica 46:217-226.

den Nijs, A.P.M. 1984. Rootstock-scion interactions in the cucumber: Implications for cultivation and breeding. Acts Hort. 156:53-60.

Elliot, G.C. and A. Lauchli. 1985. Phosphorus efficiency and phosphate-iron interaction in maize. Agron. J. 77:399-403.
Groot, S. P. C., S. Zijlstra, and J. Jansen. 1989. Powdery mildew resistance related chlorosis in cucumber, p. 61-68. In: C.E. Thomas (cd.). Proc. Cucurbitaceae 89: Evaluation and Enhancement of $\mathrm{Cu}-$ curbit Germplasm, 29 Nov.-2 Dec. 1989, Charleston, S.C.

Jansen, J., R. C.M.H. Douven, and E.E.M van Berkum. 1992. An annealing algorithm for searching optimal block designs. Biometrical J. (In press).

Hipp, B.W, and C.G. Gerard. 1969. Magnesium-phosphorus interrelationship in tomatoes. Agron. J. 61:403-405.

Howell, R.W. and R.L. Bernard. 1961. Phosphorus response of soybean varieties. Crop Sci. 1:311-313.

Kjær, B., H.P. Jensen, J. Jensen, and J. Helms Jørgensen. 1990. Associations between three $m 1$-o powdery mildew resistance genes and agronomic traits in barley. Euphytica 46: 185-193.

Kooistra, E. 1968. Powdery mildew resistance in cucumber. Euphytica $17: 236-244$

Marschner, H. and I. Caksnak. 1989. High light intensity enhances chlorosis and necrosis in leaves of zinc, potassium and manganesium deficient bean (Phaseolus vulgaris) plants. J. Plant Physiol. 134:308315.

Marschner, H., H. Oberle, I. Cakmak, and V. Römheld. 1990. Growth enhancement by silicon in cucumber (Cucumis sativus) plants depends on imbalance in phosphorus and zinc supply. Plant \& Soil 124:211-219.

McCullagh, P. and J.A. Nelder. 1989. Generalized linear models. 2nd ed. Chapman and Hall, London.

Payne, R.W., P.W. Lane, A.E. Ainsley, K.E. Bicknell, P.G.N. Digby, S.A. Harding, P.K. Leech, H.R. Simpson, A.D. Todd, P.J. Verrier, R.P. White, J.C. Grower, J.C. Tunnicliffe Wilson, and L.J. Paterson. 1987. Genstat 5 reference manual. Clarendon Press, Oxford.

Rossiter, R.C. 1952. Phosphorus toxicity in subterranean clover and oats grown in Muchea sand and the modifying effects of lime and nitrate-nitrogen. Austral. J. Agr. Res. 3:227-243.

Schwarzbach, E. 1976. The pleiotropic effects of the ml-o gene and their implications in breeding. Barley Genet. 111:440-445.

Shive, J.W. 1981. Toxicity of monobasic phosphates towards soybeans grown in soil- and solution-cultures. Soil Sci. 5:87-122.

Warren, R.G. and B. Benzian. 1959. High levels of phosphorus and die-back in yellow lupins. Nature (London) 184:1588.

Zijlstra, S., A.P.M. den Nijs, C. Sonneveld, and G. Vos. 1987. Een nieuwe aanpak van het necroseprobleem bij meeldauwresistente komkommers. Prophyta 6:138-139. 